Running head: UNDERPINNINGS OF MAINTENANCE

Potential underpinnings for community maintenance programs for sexual offenders

\author{
Carollyne Youssef ${ }^{1}$ \\ Deakin University, Australia \\ Carollyne.Youssef@outlook.com \\ Dr Sharon Casey \\ Deakin University, Australia \\ Dr Astrid Birgden \\ Deakin University, Australia
}

${ }^{1}$ Corresponding author 


\begin{abstract}
The majority of incarcerated sexual offenders will one-day return to the community. While a great proportion are likely to have participated in a custodial offence-specific treatment program, knowing what happens to this 'acquired' knowledge and skill once they are released and how this influences the desistance process remains unclear. Research on offender rehabilitation often focuses on the efficacy of custodial treatment interventions for offenders, while studies examining post-release programs for offenders has some untapped potential. Further to this, an understanding of the theoretical underpinnings for any community maintenance-type programs for offenders remains relatively untouched in the offender rehabilitation literature. Thus, this paper attempts to explore some of the potential theoretical underpinnings for community maintenance programs for sexual offenders. Consideration will be given to the definition of such programs, some of the theories that may inform these programs, and the incorporation of desistance theory into maintenance programs.
\end{abstract}

Keywords: Sex offenders, maintenance programs, desistance, reintegration, community programs 


\section{Potential Underpinnings for Community Maintenance Programs for Sexual Offenders}

There is a pervasive focus in the sexual offender rehabilitation literature on treatment program content, duration, intensity, and efficacy (Mann \& Fernandez, 2006). Attention is also frequently paid to the aetiological assumptions of sexual offending (Mann \& Fernandez, 2006). These theories inform program development, underpinning the rationale for behaviour change and the hypothesised reduction in recidivism (Payne, 2010). However, a consistent oversight in the offender rehabilitation literature is what happens to offenders after their participation in a (custodial) treatment program or a comprehensive theory of change. There is a dearth of information available regarding post-release or aftercare programs, such as community maintenance programs. Given the number of offenders who enter such programs, there is a need to ask questions about the nature and purpose of these programs, for example, what follow-up or aftercare interventions are available to assist offenders with their re-integration process; what theories or paradigms inform post-treatment interventions for offenders; and how do offenders cease their offending behaviour.

Some researchers have argued that the degree of support and assistance offered during the period post-release is crucial to determining whether an offender will experience a successful reintegration process (e.g., McNeill, 2006; Porporino, 2013; Rex, 1999). While an offender may complete an intensive offence-specific program whilst in custody, the process of maintaining any programmatic gains or changes remains unclear, and there may be an assumption that these gains or changes have indeed taken place which can present an interesting confound. Furthermore, the process whereby newly acquired skills are generalised is understudied for released offenders who have completed a custodial offencespecific treatment program. How then are newly acquired skills manifested once the offender returns to life in the community? And are these apparent manifestations sufficient to 
contribute to a desistance process that would ideally follow? These questions are highly relevant to sexual offenders given the social fear associated with such offenders and the legislative changes ${ }^{2}$ that make it more difficult for sexual offenders who are released into the community to reintegrate and become part of the community.

Although the concept of maintenance programs makes therapeutic sense with evidence supporting reductions in recidivism with post-release support (Borzycki \& Baldry, 2003; James, Stams, Asscher, De Roo \& van der Laan, 2013; Johnson \& Cullen, 2015; Wilson, Cortoni \& McWhinnie, 2009; Wilson \& Picheca, 2005; Wilson, Stewart, Stirpe, Barrett \& Cripps, 2002), such programs lack a strong theoretical foundation which serves to limit the clarity of their application in practice (Day \& Casey, 2010; Youssef, 2013). The aims of this paper, therefore, are threefold. In view of the role of post-release programs, the first aim will be to conceptualise the notion of change and what that means for sexual offenders who enter a post-release maintenance program. Second, the paper will attempt to define the term "community maintenance program" and explore some of the possible theoretical underpinnings for such programs (e.g., the Personal, Interpersonal and Community (PIC) perspective and the Risk-Need-Responsivity model (RNR), Relapse Prevention, and the Good Lives Model (GLM)). Finally, the relevance of desistance theories to maintenance programs will be considered and the implications this has for practice. For the purpose of this paper, the focus will be community maintenance programs for sexual offenders (adult and child victims) who have completed a custodial offence-specific treatment program. Consequently, monitoring, surveillance strategies and other reintegrative activities (e.g. employment) undertaken in the community will be excluded from the discussion.

\footnotetext{
${ }^{2}$ For example, Extended Supervision Orders (ESO) in Australia and New Zealand; Sexual Risk Orders (SRO) and Sexual Harm Prevention Orders (SHPO) in the UK; and Sexual Offender Civil Commitment (SOCC) procedures in some states in the US.
} 


\subsection{Change}

Prior to considering which factors might assist an offender to maintain change, it is important to first consider how change itself is conceptualised; how it is achieved and identified in people who undertake a treatment program. In so doing, one issue that becomes apparent is the lack of a unified conceptual understanding of what constitutes behavioural or cognitive change within the psychological literature (Evans, 2013). A unified account of change ensures that the descriptions, causes, concepts and process involved in an explanation of a change process cannot be inherently contradictory (Evans, 2013). For instance, when considering sexual offending behaviour there is no unified theory regarding the maintenance or cessation of the behaviour. Some approaches attribute change to the degree of social support (i.e., desistance-focused approaches) and others to the management of risk factors or changes in criminal cognitions (i.e., RNR focus).

Change can be defined as creating "difference within the human condition, typically in terms of functioning, and ranging from dysfunctional to functional" (Carich, et al., 2013, p. 190). Two levels of change are usually defined, the first order refers to superficial change or change within the system, while second order change involves a systemic transformation. A higher level of change has also been proposed, at the meta-level referring to ongoing deeper levels of change (Carich, et al., 2013). When applied to sexual offenders, at the first order, change occurs when the offender stops their offending behaviour. At the deeper level of change, changes in core schemas or implicit theories occur. Implicit theories are the basic templates guiding one's behaviours. Dysfunctional implicit theories are hypothesised to be involved in offending states and decisions, which therefore require the deepest levels of change in order to replace those implicit theories. While the first order would presumably require less effort, the second order is longer term and requires ongoing effortful intervention and application. 
Change requires that new behaviours (including cognitions) become more likely to occur, therefore people need to practise their new skills. These new skills can be practised within a clinical environment, such as in the group room in gaol, but this is usually the wrong cue complex (Evans, 2013). It is much more productive to practise new skills in the setting in which they will need to be used, or when confronted with stimuli that will likely trigger the old, unwanted behaviour or response. As change becomes more active in nature, true maintenance cannot be assessed if the individual has few chances to engage in the behaviour (Martin, 2012). Offenders in custody may feel or think they have changed but in the absence of exposure to the triggers, negative influences and stressors they may normally encounter in their daily lives, it is difficult to determine this. This means that offenders may believe they have changed upon entry into community maintenance, when they have not actually had the opportunity to test whether they have or not, thus the significance of post-treatment programs.

A limitation of the current approaches to offending behaviour is that interventions tend to operate from a premise that change principles are related to specific 'problems'. The focus remains on treatment-specific strategies rather than exploring more universal principles such as those found in Maslow's $(1943,1954)$ hierarchy of needs (see Paul, 2014). In other words, some of the foundational aspects of human change tend to be ignored by forensic researchers and practitioners, who focus on pathology related to offending behaviour, at the expense of more universal human behaviour. This focus on pathology, or more specifically offending behaviour, presumably limits the generalisability of interventions and thus may limit the generalisability of any changes as a result of these interventions. This has significant implications for any post-treatment programs, such as maintenance programs.

\subsection{What Maintenance is not}

While the concept of having a maintenance program appears to 'make sense', there 
does not appear to be a universal definition of what a maintenance program is or indeed, a standardised method to maintenance for offenders (Youssef, 2013). What does seem apparent is that the terms aftercare, through-care, booster sessions, relapse prevention and maintenance are used interchangeably despite the terms seemingly referring to different types of services. In an attempt to differentiate these programs from maintenance, this section will first provide a brief overview of each before turning to the issue of attempting to define maintenance programs and reviewing what appear to be its theoretical underpinnings.

Aftercare is a term often used within correctional settings. Services are less formal compared to offence-specific programs for example, aimed at assisting offenders with practical needs such as housing, employment, and community services once released. This approach is consistent with evidence from the psychology and health spheres which indicates that individuals with problems are more likely to succeed or recover when they have genuine care and assistance from others (Wilson \& Picheca, 2005). Translated to an offender rehabilitation context, individuals are more likely to succeed when re-entry to society is facilitated by informed parole supervision and appropriate human service (Wilson et al., 2002). Circles of Support and Accountability (COSA) is an example of an aftercare program for sexual offenders operating primarily to support high risk offenders who have little to no social support in the community. The Circle meets weekly to discuss how the offender is coping and progressing and involves reviewing their activities as well as scheduling group and individual meetings (Hanmen \& Petrunik, 2007). The meetings are usually quite casual and can include meeting at a café for coffee or lunch. Volunteers assist the offender with running errands and attending appointments. The aim of individual meetings is to facilitate and foster a trusting relationship and companionship, thought to be essential to the offender's successful reintegration. Contact between the offender and support worker occurs at least weekly and in cases of a crisis or emergency, the support person is available at any time 
(Hannem \& Petrunik, 2007). Offenders commit to a minimum of one year with the program and after that period, the offender may choose to maintain the same level of contact, have less frequent contact, or cease contact with the Circle.

Research supports the effectiveness of the COSA program with studies indicating that offenders who participate demonstrate lower recidivism rates (e.g., Bates, Williams, Wilson \& Wilson, 2014; Wilson, McWhinnie, Picheca \& Prinzo, 2007; Wilson \& Picheca, 2005). However, while support is integral in the successful reintegration of offenders and the 'accountability' component of COSA can assist to address issues related to offending behaviour, other psychological factors may be deemed essential in order to maintain psychological/criminological change. These include factors more directly linked to offending behaviour (e.g., antisocial lifestyle; deviant sexual interests). In this sense, COSA would not be equivalent to a maintenance program as there is no capacity for the volunteer support providers to address high-risk situations, criminogenic needs, or offer assistance to offenders within a therapeutic or psychological capacity.

Another term used is through-care, which often refers to linking offenders with community services and adopting a multi-disciplinary approach to offender reintegration. A central concept of through-care is continuity of care and the seamless delivery of services (ACT Government, 2011). Through-care differs from aftercare as described above, as it is not usually carried out by volunteers but is commonly the responsibility of community service providers and driven by correctional services, and delivered as a component of casemanagement. Case-management involves assessing the needs of the offender and involving the appropriate services and agencies necessary to assist with reintegration whether the support is for accommodation, financial assistance, mental health issues, employment, or drug use (Healey, 1999; Turner, 2010). According to Taxman and Bouffard (2000), the implementation of transitional and/or support services (including support groups, 
employment assistance, vocational training and counselling) are critical to the rehabilitative process. However, this process of linking offenders with community services in order to meet their more immediate needs and help them stabilise, suffers from the same limitations as after-care in the context of defining maintenance. While the activities involved may be imperative to an offender's successful re-entry into the community, no therapeutic intervention is involved nor is the approach underpinned by psychological theory (i.e., theory of change; desistance from crime theories).

Booster sessions are described as meetings that occur less frequently than the initial program they follow and usually allow participants the opportunity to review course material, ask questions, discuss issues, and receive additional support (Vaterlaus, 2009). These types of sessions are sometimes used as components of maintenance programs. Most often recommended to re-establish or reinforce the cognitive messages or behaviour changes brought about in therapeutic and behavioural interventions and to strengthen habit formation (e.g., Fleig, Pomp, Schwarzer \& Lippke, 2013; Hennessy et al., 1999), research into their effectiveness has revealed the potential value of booster sessions in terms of (1) the maintenance of gains, (2) the recovery of lost gains, and (3) reinforcing the level of postprogram gains (see Vaterlaus, 2009). However, smaller doses of treatment such as this are conceptually different to what a 'psychological' maintenance program might entail. Merely repeating content that has already been covered in treatment may be ineffective, in addition to being a waste of resources, if done in isolation (Day \& Casey, 2010). While the value of occasionally revising treatment content may be required or necessary, having this as a primary focus of a post-treatment program does not appear to be warranted in the absence of other targets (Youssef, 2013). This leaves the issue of providing a definition for the term maintenance program and conceptualising what such a program entails. One of the difficulties in so doing appears to be linked to the absence of stated goals in many 
maintenance programs, an issue raised by Day and Casey (2010):

"Are they, for example, intended to reinforce the skills acquired during the treatment, or to remind offenders of their commitment to change and perhaps reinforce the plans they developed in treatment to implement change? Perhaps they also aim to offer social support and encouragement, or simply offer a means to monitor risk over an extended period of time.” (p.450).

This section briefly discussed some of the terms used to refer to some sort of aftercare service for offenders, however as can be gleaned these terms do not quite constitute what a maintenance program may be. The next section will offer a definition of what a maintenance program may be.

\subsection{Maintenance for Offenders - A possible definition}

As discussed above, it seems that several different terms such as aftercare, throughcare or booster sessions are used interchangeably, however they refer to different services. When considering what a maintenance program may be, it seems that these terms can be mistaken for maintenance, however there is currently no clear conceptual definition of what constitutes a maintenance program for offenders. This also places ambiguity on the basic contextual aspects of maintenance programs, such as duration, frequency and content (Heseltine et al., 2009; Youssef, 2013) as well as the more foundational aspects of a program, such as the theoretical underpinnings.

In order to consider the definition of what a maintenance program is, the maintenance of change needs to be briefly considered. Maintenance of a change has been defined by Evans (2013) as "the continuation of behavioural patterns either in the absence of the therapeutically engineered controlling conditions that caused it or in the transfer of control from therapeutic 
conditions to comparable conditions in the natural environment" (p. 35). In other words, maintaining behaviour change requires generalisability and transferability, in the absence of therapeutic factors which may have resulted in the change initially. While this is one view of what the maintenance of change may be, this is not explicitly articulated when maintenance programs for offenders are considered.

Taking the abovementioned issues into account, community maintenance programs for offenders can ideally provide an opportunity for the enhancement of skills acquired in treatment to be actively rehearsed in a genuine setting (i.e., the community or natural setting). If possible, maintenance would constitute a period of reintegration which allows offenders an opportunity to demonstrate 'newly acquired' behaviours (Youssef, 2013).

Two targets would appear critical in the delivery of maintenance programs. The first is assisting with the successful reintegration of offenders into the community, which entails stability in basic areas such as accommodation, employment (or regular income), and social support. It would seem basic needs such as these must be met before offenders can be expected to focus on higher level needs, such as emotion regulation, meaningful and satisfying interpersonal relationships, and self-actualisation (Youssef, 2013). For example, Willis and Grace $(2008 ; 2009)$ identified that planning for accommodation, employment and social support combined, provided the best predictive model for predicting sexual recidivism for child sex offenders.

The second goal would be maintaining treatment gains so that offenders can manage their risk(s), if and as these arise. This requires the offender to be able to identify high risk situations, events, and states, and be able to implement effective management strategies in order to avoid reoffending. In this respect, maintenance would provide additional support and 'revision' as needed (e.g., in the form of supplementary booster sessions), as offenders face situations that increase their vulnerabilities or susceptibilities for reoffending. Hanson 
and Harris (1998) noted that minimal social support, poor self-management strategies, increased anger, and subjective distress were present in their sample of men who sexually reoffended. Offenders need to be able to do more than just avoid high risk situations and states. Ideally, they need to be able to start to establish a narrative and identity as a desister from crime and work towards living a more fulfilled life.

It is important to note that behaviours which are motivated by impulses require different cessation strategies from behaviours that are instrumental, with a greater focus on the outcomes they achieve (Evans, 2013). A focus on the current maintaining variables becomes pragmatic, even though effective solutions may be unrelated to the cause of the initial problem. Being able to understand exactly how behaviour develops can make it easier to change that behaviour however such knowledge is not always possible and behaviour can change without knowing its exact aetiology (Paul, 2014). If there is a focus on the factors that promote change rather than those that create the problems, then interventions can be more easily devised despite these early factors.

When an offender has completed an offence-specific program, it is not always entirely clear what has changed or what gains have been made. Although most programs have a test battery pre- and post-intervention, research finds that these psychometrics do not always reflect change (see Barnett, Wakeling, Maderville-Norden, \& Rakestrow, 2012; Marshall et al., 2011). These issues have significant implications for maintenance programs in terms of identifying what has changed, what has not changed, and what needs to be maintained with the goal of desistance (i.e. the cessation of criminal behaviour) at the forefront.

The limitations regarding treatment interventions can have an impact on maintenance programs, particularly if maintenance programs are limited to a "follow-on" or "phase two" of treatment intervention. In other words, if a maintenance program is conceptualised as a 'phase two' of treatment, then the limitations present at the treatment stage have a high 
likelihood of continuing into maintenance - particularly if the typical treatment targets (i.e., criminogenic needs) are not correlated with desistance, which in theory should be the underpinning of community maintenance programs. Furthermore, the contextual difference between a custodial treatment program and a community maintenance program already allow for fundamental program differences to exist (Casey, Day \& Howells, 2005).

Maintenance for offenders who are released may need to take a different approach, a slightly separate approach to that which custodial interventions do. The needs of offenders in the community are essentially different to those who are still serving their sentence in custody. Maintenance programs need to be designed so that they can address these unique features of offender re-entry and reintegration and maintenance programs are in a unique temporal position of being able to assist with the desistance process, in a way in which a custodial treatment program are not.

Those correctional agencies that do provide something akin to a maintenance program tend to have specific entry criteria including prior participation in an offence-specific program and a well-developed post-treatment plan. However, diversity seems to be apparent in practice, with some agencies offering a follow-up or maintenance-like component, either within a voluntary capacity or as a compulsory and mandated requirement while other correctional agencies offer none at all (Day \& Casey, 2010; Howells, Heseltine, Sarre, Davey, \& Day, 2004). Even where specifically identified maintenance programs are available, considerable differences in the length of time an offender participates are noted. In Australia, for example, some states offer a short, 12-week community maintenance program (i.e., Queensland) whereas others require offenders to participate in the maintenance program for up to several years (i.e., New South Wales) (see Heseltine, Day, \& Sarre, 2009). What seems to be a common issue is the lack of a theoretical underpinning for maintenance programs. 


\subsection{Maintenance: Potential Theoretical Underpinnings}

In terms of theoretical approaches that might inform maintenance, five are particularly relevant: the Relapse Prevention Model (RP; Marlatt \& Gordon, 1985), the Personal, Interpersonal, and Community Reinforcement perspective (Andrews \& Bonta, 2010) and the Risk-Needs-Responsivity model (PIC-R; RNR; Andrews \& Bonta, 2010), the Good Lives Model (GLM; Ward \& Maruna, 2007; Ward \& Stewart, 2003a) and desistance theories (e.g., Maruna, 2001; Sampson \& Laub, 1993). Each will be examined briefly and their applicability to maintenance programs considered.

\subsubsection{Relapse Prevention for sex offenders: The genesis of maintenance programs for offenders.}

Relapse Prevention (RP) was originally developed for the treatment of substance addiction and was designed to assist people who had ceased their addictions to maintain abstinence (Marlatt \& Gordon, 1985). Its aim is to enable people to prevent a relapse, and thereby maintain the new behaviour. Derived from social learning theory (Bandura, 1977), the original RP model was intended as a post-treatment maintenance program (Marlatt \& Gordon, 1985). When applied to sexual offending behaviour, however, it has been incorporated into both treatment and maintenance programs.

In the sexual offender domain, RP has been defined as a maintenance-oriented selfcontrol program that teaches offenders how to determine if they are entering into high-risk situations, self-destructive behaviour, deviant cycle patterns, and thus a potential reoffence (Laws, Hudson \& Ward, 2000). The basic principles of model with sexual offenders are the same as with addictive behaviour, that is; that addictive behaviours are determined by past learning experiences, reinforcement contingencies, situational antecedents and cognitive expectations or beliefs. A lapse is defined as a single incident of the addictive behaviour 
whereas a relapse refers to the full reinstatement of pre-intervention levels of the addictive behaviour. Pithers (1990) outlined a RP program for sex offenders based on the idea of a cognitive-behavioural chain, a similar construct to the relapse process. According to Pithers' model of the relapse process,

"the offender is initially in an abstinent state with high self-efficacy beliefs regarding the avoidance of sexual offending. However, with the advent of apparently irrelevant decisions, a high-risk situation emerges which, if not coped with effectively, results in a lapse. For example, the apparently irrelevant decision to accept a neighbours' request to baby-sit their child may result in a high-risk situation. Failure to cope effectively with this situation could potentially lead to a lapse (e.g., sexual fantasies about children)" (Ward, Purvis \& Devilly, 2004, p.191).

When RP is applied to sex offenders in the community, several principles guide their management (Cumming \& Buell, 1996). First, there is an assumption that treatment will not "cure" the offenders of their desire to offend or their deviancy; offenders can learn new skills to stop enacting the offending behaviour, but the interests may not be eradicated. Second, it is expected that the offender will be an active participant in identifying their risky behaviours and high risk situations. Third, due to self-reporting of risk behaviour being unreliable, it is essential within the RP model that the offender develop a support network which can continue to monitor their behaviour. Finally, responsibility for ceasing offending behaviour is assumed to lie solely within the offender. In using RP as a strategy to manage sex offenders in the community, supervisors or case managers focus only on factors associated with the individual's risk and directly related to their offending behaviour and do not focus on any other factors (Cumming \& Buell, 1996). For example, if employment was not related to an individual's offending, RP then considers employment not a priority nor is it to be addressed. 


\subsubsection{Critique of the RP.}

The use of RP with sexual offenders has been critiqued and several criticisms and limitations of its use with this population have been raised (Ward \& Hudson, 1998). One primary criticism is in relation to cessation and maintenance. There is an inherent assumption that individuals who undertake RP have ceased their problematic behaviour although this is not always the case (Laws et al., 2000). For example, some offenders continue to engage in their offending behaviour whilst in prison (i.e., offending against other inmates or staff) or continue to fantasise about their offending or deviant behaviour. There is also an assumption that sexual offenders want to change their behaviour; again, is not always the case. RP is not a cessation-oriented approach and, therefore, it is difficult to induce the motivation to stop offending, especially when used with unmotivated people (Laws, 2003).

Other criticisms of the RP approach include: a narrow focus on offence pathways; an emphasis on avoidance goals; a negative orientation to intervention; and insufficient opportunity to practise skills taught (see Carich, Wilson, Carich, \& Calder, 2013). According to Thakker and Ward (2010), the five main criticism of the RP model which would apply equally to sexual offender maintenance programs are: (1) RP is weak in its capacity to establish therapeutic engagement with offenders, paying insufficient attention to the therapeutic alliance; (2) RP does not acknowledge the role of narrative identity and offender agency; (3) RP does not pay attention to personal goods ${ }^{3}$ (i.e., does not focus on how offenders can meet their primary needs); (4) RP can be quite rigid at the expense of individual needs; and (5) RP overemphasises the importance of risk to the neglect of other important factors. Nonetheless, it is important to highlight that RP has contributed significantly to the

\footnotetext{
${ }^{3}$ Discussed in the section 'Good Lives Model'.
} 
concept of maintenance in that it has highlighted the importance of a maintenance phase to intervention and change by incorporating the stages of change model.

\subsubsection{PIC-R Theory}

The PIC-R perspective (Andrews \& Bonta, 2010), which is based on a general personality and cognitive social-learning theory of criminal behaviour, has informed the vast majority of current rehabilitation programs and particularly the RNR model (Ward \& Maruna, 2007). Human behaviour is seen to be under personal, interpersonal, and automatic control (Andrews \& Dowden, 2007) with individual differences deemed important in terms of the level of self-control an individual can exert on personal behaviour. This capacity is influenced by the individual's own specific skills (e.g., problem solving ability, ability to selfmonitor and evaluate behaviour, to cope with temptation), and personal standards regarding behaviour (e.g., attitudes, beliefs, values, rationalisations, identities).

PIC-R considers factors that actively encourage or discourage criminal activity, by incorporating elements of both motivational and control theories. It recognises that understanding offending behaviour requires knowledge from the biological, human and social sciences areas in general, but also emphasises behavioural and social learning principles because of their demonstrated functional power in applied settings. PIC-R draws upon radical behaviourism for its most fundamental principles, in that the factors "responsible for variation in human conduct are found in the immediate situation of action. Specifically, these include rewards or costly consequences for particular acts. The theoretical principle is that the variation in the immediate contingencies of action are responsible for the acquisition, maintenance and modification of human behaviour" (Andrews \& Bonta, 1998, p. 150).

According to the PIC-R several factors that may influence whether an individual engages in offending behaviour: the presence of anti-social attitudes, associating with 
antisocial peers, having a history of offending and antisocial personality traits. Further influences, although not considered as significant, include familial problems and lack of social achievements, such as in work and school. Thus, according to this theory, in order to minimise an individual's risk of engaging in offending behaviour, these factors need to be addressed. It is this theory which has ultimately informed the development of the RNR model (Ferguson, 2002).

\subsubsection{Risk-Needs-Responsivity (RNR) Model}

The long-term goal of any intervention or model for sexual offender treatment is for offenders to ultimately cease offending. The question is: How do programs achieve this? Is it by focusing on those factors which caused the individual to offend in the first place or is it to approach the individual's needs, general life quality and satisfaction? The PIC-R and the Risks, Needs and Responsivity (RNR) model (Andrews \& Bonta, 2010) are rehabilitation theories of effective correctional intervention with a number of assumptions. First, there is the assumption that the best way to reduce recidivism is through reducing or eliminating dynamic risk factors. Second, in order to reduce harm to the community there needs to be the management of dynamic (or treatable) risk factors. Third, clinical needs not problems should be explicitly targeted. Last, risk assessments should direct the treatment process (Andrews \& Bonta, 2010; Ward, Polaschek, \& Beech, 2006).

The RNR model identifies and seeks to understand risk factors which are related to, and can predict, offending behaviour. Static and dynamic risk factors are identified as significant. Static factors refer to those factors which are presumed not to change over time and are not amenable to change through intervention but they are considered to predict the risk of re-offending. Examples of these factors include victim characteristics and offence history. Conversely, dynamic risk factors are thought to be amenable to change through 
intervention and are often targeted in assessments and programs for offenders. Dynamic risk factors are usually referred to as criminogenic needs and are considered important in reducing the risk for recidivism, such as an antisocial lifestyle (see Andrews \& Bonta, 2010).

The RNR model of offender rehabilitation stipulates key principles including risk, needs, responsivity and discretion (Andrews \& Bonta, 2010). The risk principle suggests that an offender's risk needs to be matched to the intensity of service provided, in other words, high risk offenders require a greater intensity of services. The needs principle recommends that intervention should target the needs which are associated with recidivism and that can be changed. Reponsivity refers to the need for interventions to be delivered in a way as to be well received by offenders and understandable, addressing characteristics within the individual and the person-environment interaction.

Responsivity accounts for a lot of the observed treatment changes and has two components; general and specific. Specific responsivity refers to the therapist adjusting their approach to the unique features of each offender, including both enduring features such as intellectual capacity and personality traits as well as day-to-day fluctuations in mood and motivation (Marshall \& Marshall, 2014). General responsivity includes the need for the therapist to display the factors associated with developing an effective therapeutic alliance. This includes the ability to demonstrate "features of warmth, empathy, respect, and support while modelling and reinforcing prosocial attitudes and behaviour" (p. 164, Marshall \& Marshall, 2014). In fact, when properly enacted, the responsivity principle can elicit an effect size in excess of 0.23 (Marshall \& Marshall, 2014).

There are a few criticisms of the RNR model, with one of them being the use of the term 'needs'. Ward and Stewart (2003b) stated that when the definition of need is applied to risk factors in sex offenders, there is a suggestion that offenders have a need to act impulsively or are preoccupied with sex. Rather, dynamic risk factors should be viewed as 
obstacles to fulfilling a need rather than a need in and within themselves. Thus, rather than eliminating risk factors, treatment should be concerned with assisting offenders to develop prosocial methods of fulfilling their basic needs. Furthermore, the RNR model also appears to fail to detail the causal mechanisms underlying dynamic risk factors or criminogenic needs and ultimately offending behaviour. This makes it difficult for therapists to develop specific treatment targets. Another criticism is that the responsivity principle is underdeveloped or not an influential aspect of the RNR model. This is a key issue for offender engagement and motivation since it is linked to when and why offenders may make substantive commitments to change (McNeill \& Weaver, 2010).

\subsubsection{PIC-R, RNR and Maintenance}

As noted by Day and Casey (2010, p. 451), an application of the PIC-R to maintenance suggests such programs might serve several functions including (a) sustaining an ongoing commitment to change; (b) considering an offender's personal goals; and (c) behaviour change should be reinforced over time and rehearsed until such time that it becomes automatic. While the PIC-R recognises the main interpersonal settings in which behaviour occurs (i.e., families, workplaces, schools, leisure), it also takes into account the many other sources of influence on human behaviour (i.e., historical, geographical, politicaleconomic).

With regards to the RNR model and its applicability to community maintenance programs, the following principles may be applied;

i) Only those offenders who are identified as high risk are expected to participate in a community maintenance programs. Alternatively, higher risk offenders may be required to participate in maintenance at a high intensity (i.e., weekly) and for a longer period of time compared to those offenders who are moderate 
risk.

ii) Maintenance programs are an extension to treatment interventions whereby the focus is on criminal attitudes, criminal thinking, negative associates and other factors related to the 'big eight' .

iii) A community maintenance program would take a CBT approach.

\subsubsection{Good Lives Model}

The Good Lives Model (GLM; Ward \& Stewart, 2003a) of offender treatment is basically a strengths-based approach (Ward, 2002). The primary aim is to equip offenders with the necessary internal and external capabilities to secure primary human goods in socially acceptable ways (Ward \& Stewart, 2003a). The central premise is that all human actions reflect attempts to achieve primary human goods. Primary goods are conceptualised as "actions, states of affairs, characteristics, experiences, and states of mind that are viewed as intrinsically beneficial to human beings and are therefore sought for their own sake rather than as a means to some more fundamental ends" (Ward \& Stewart, 2003a, p. 356). Primary goods are considered to emerge from basic needs, whereas instrumental or secondary goods provide practical ways of securing these goods.

Eleven primary human goods have been identified: life (i.e., healthy living and optimal physical functioning, sexual satisfaction); knowledge; excellence in work (mastery); excellence in play (mastery); excellence in agency (i.e., autonomy and self-directedness); inner peace (i.e., freedom from emotional turmoil); relatedness (i.e., intimate, romantic and familial relationships); community; spirituality (finding meaning and purpose); happiness; and creativity (Laws \& Ward, 2011;Ward \& Brown, 2009; Ward, Gannon \& Mann, 2007).

\footnotetext{
${ }^{4}$ History of antisocial behaviour; antisocial personality pattern; antisocial cognition; antisocial associates; family/martial circumstances; school/work; leisure/recreation and; substance abuse (see Andrews \& Bonta, 2010 for further information).
} 
For each of these primary goods, secondary goods are described, which provide the means of acquiring the primary goods. For example, in order to meet the primary good of knowledge the individual may attend school or participate in training in order to meet that need. When considering offending behaviour, an offender may attempt to meet the primary human good for relatedness by sexually offending against a child. The goal would then be to assist the offender in meeting that primary good through a different, non-offending secondary good that replaces the maladaptive secondary good.

According to the GLM, all individuals set out to achieve primary human goods. However, with sexual offenders it is theorised that their sexual offending occurs in the context of attempting to achieve these goods in the absence of any other perceived options. Therefore, treatment should aim to instil knowledge about needs and the ways in which to achieve the identified human goods in order to lead satisfying lives (Harkins, Flak, Beech \& Woodhams, 2012). This also requires that treatment take a more positive approach focusing on individual strengths, increasing an individual's self-worth and assisting in the enhancement of skills.

\subsubsection{GLM and Maintenance}

The GLM could be applied to maintenance in focusing on the individual's primary goods and how to best meet them in the community. The GLM combined with a desistance focus is founded on the assumption that it "aims to instil or repair offenders' agency conditions by way of basic therapeutic interventions" (Laws \& Ward, 2011, p.234). Because the GLM is a rehabilitation theory and not a therapy model, its function is to provide therapists and service providers with guidance as to the overall purposes and goals of intervention, how these programs can be constructed and implemented and what type of relationship should be cultivated with the offender (Laws \& Ward, 2011). In this respect the 
GLM can be applied to maintenance programs in three possible ways:

i) desistance factors such as work, relationships or education may be available to an offender upon release, so there may be some degree of assistance and liaison by service providers regarding family and community factors;

ii) some intervention may be needed to assist the offender to 'take advantage' of desistance opportunities, along the lines of repair (i.e. learning how to apply skills in different contexts); and/or

iii) if intensive intervention work is still required for an offender, so that there is a significant lack of psychological capabilities and/or social supports then maintenance intervention needs to instil the internal and external conditions required for an offender to be able to meet their primary goods (Laws \& Ward, 2011).

\subsection{Maintenance and Desistance}

Most people are familiar with the term "desist", with words like "ceasing" or "stopping" coming to mind. However, the concept of desistance when applied to criminal behaviour has many different definitions and this perhaps has contributed to the inconsistencies in the literature regarding this phase of an offender's change cycle. Some theorists/researchers have defined desistance as a distinct period in time, while others insist on desistance being a life-long process which is difficult or almost impossible to pinpoint at any given time until death (Bushway, Piquero, Broidy, Cauffman, \& Mazerolle, 2001). Laws and Ward (2011) offer the following definitions including: desistance being a self-reported cessation of criminal activity, a cessation of official criminal behaviour (i.e., criminal record), a gradual slowing down of criminal behaviour, and a marked decrease in the frequency, degree and severity of criminal behaviour. 
A distinction is often made between primary and secondary desistance (Weaver \& McNeill, 2013). Whereas primary desistance refers to any crime-free period in the course of a criminal career, secondary desistance is defined as the movement from the behaviour of non-offending to the assumption of a role or identity of a non-offender or 'changed person'. In other words, primary desistance would occur for short, sporadic periods of time, perhaps a few weeks or months and tends to refer to a lull in criminal behaviour, while secondary desistance would involve a more prolonged and sustained period of time and tends to be more long lasting. In reviewing the theories offered towards the causes of desistance, three main areas are mentioned relating to age and maturational reform, life transitions and the associated social bonds, and narrative changes in personal and social identity.

A community maintenance program takes place at a temporal point when offenders can commence the desistance process, thus when considering the purpose of maintenance programs, the issue of desistance is invariably associated. A major unanswered question regarding desistance is whether the predictors of desistance are different to or simply the opposite of the predictors which lead to offending behaviour (Sampson \& Laub, 2003). This distinction has implications for the delivery and focus of maintenance programs. A number of explanations of desistance have emerged although they are by no means discrete or mutually exclusive. Two of these explanations are classed as ontogenetic (Bushway et al., 2001; Maruna, 2001) whereby desistance is thought to follow set biological and physiological pathways, and three are categorised as sociogenic, whereby desistance is seen as a product of the interactions between the broader social context and the desister (Laub \& Sampson, 2001; Sampson \& Laub, 2004). See Table 1. 
Table 1.

Models and frameworks of desistance

Framework/model

Explanations of desistance

Maturation and aging accounts of desistance

Developmental accounts of desistance
Framework I - Lack of maturity is a cause of persistent recidivism. Maturation in this sense involves the development of physical, intellectual and affective capacity and stability and an of integration of temperament, personality and intelligence (Glueck \& Glueck, 1974).

Framework II - The idea is that desistance "just happens" as an offender ages. (Gottfredson \& Hirschi, 1990).

Framework I - Desistance is conceptualised as normative and expected across one's lifespan and cognitive change is an antecedent to behaviour change. "Identity deconstruction" is seen as necessary to commence the desistance process (Maruna, 2001; Neugarten, 1996; Shover, 1996).

Framework II - Biological and psychological factors contribute to the cessation of offending behaviour. Ontogenetic and sociogenic models are merged. The peak and decline in physical strength, energy, psychological drive and the need for stimulation underscores the peak and decline in criminal behaviour (Gove, 1985).

Framework III - Life-course persistent offenders start early in childhood and persist in offending, they do not desist from crime due to "the constant process of reciprocal interaction between personal traits and environmental reactions to them" (Moffitt, 1994, p.28). On the other hand, adolescence-limited offenders are involved in antisocial 
behaviour only during adolescence. Delinquency is seen as situational, with no history of antisocial behaviour in childhood. These offenders desist in response to changing contingencies and reinforcements (Moffitt, 1994).

Life-course accounts of

A focus on permanence and change in criminal behaviour

desistance over time, including its relation to historical and other contextual factors of social life. Prominent life events thought to influence behaviour and modify trajectories (Sampson \& Laub, 1993). The question is how these particular life events, (e.g. work, marriage, military) effect social bonds and informal social control.

Rational choice accounts of desistance

Social learning accounts of desistance
A conscious reconsideration of the costs and benefits of crime underlies the decision to desist (Clarke \& Cornish, 1985). These decisions are related to changes in the moral tolerance for criminal behaviour (Paternoster, 1989).

"Differential association with noncriminal peers and significant others, less exposure to or opportunities to model or imitate criminal behaviour developing definitions and attitudes favourable to conformity and abiding by the law, and differential reinforcement . . . discourage continued involvement in crime are all part of the desistance story" (Laub \& Sampson, 2001, p. 46). Marriage is important in desistance because it can reduce, weaken or sever ties with antisocial influences (Warr, 1998).

Note: Models and frameworks adapted from, Understanding desistance from crime, by J. Laub and R. Sampson, 2001, Crime and Justice, 28, 1-69. References all cited in Laub and Sampson. Copyright 2001 by the University of Chicago.

As noted by Laws and Ward (2011), one needs to question any assumption that a treatment program lasting 6-12 months is capable of producing profound intrapersonal changes that would last for ten years or longer. Perhaps treatment offers and equips offenders 
with the tools to be able to maximise on the opportunities that present for desistance to take place, however whether treatment itself per se directly impacts on desistance remains unknown. This does not undermine the significance of treatment programs for offenders, but places it as more of a contributory factor to desistance as opposed to a causal factor. Other factors can be considered as significant in assisting offenders on their desistance journey, including social supports.

Desistance encompasses the wider circle ${ }^{5}$ around offenders including families, communities and cultures and is not only about individuals and their abilities and skills (Farrall, Sharpe, Hunter \& Calverley, 2011). It is therefore vital when considering maintenance programs that the familial, community and cultural factors be taken into account and in fact incorporated into any attempts to assist offenders to reintegration and maintain treatment changes.

At the maintenance stage offenders are in the community and the capacity for them to reintegrate and implement treatment changes is considered a focus. Therefore, it is important to examine what factors have been identified as significant for those offenders who cease their offending behaviour in order to determine targets in a maintenance program. While ongoing monitoring and awareness of an offender's risk factors may be useful in the immediate release from prison (i.e., RNR focus), longer term goals and meaningful attachments and activities are perhaps more important and contribute to secondary desistance (i.e., GLM focus).

\subsection{Dominant Approaches to Offender Intervention}

\subsubsection{RNR vs GLM, and a place for desistance theory?}

\footnotetext{
${ }^{5}$ Social capital refers to the network of social and/or relational connections that exist between people, based on norms of reciprocity and mutual assistance, through which most of us achieve participation in society (Fukuyama, 2001; Weaver \& McNeill, 2011). Social capital cannot be underestimated in its influence and necessity to encouraging desistance.
} 
Neither the GLM nor RNR appear to have been considered in relation to community maintenance programs. Although several differences have been highlighted between the RNR model and the GLM, the main difference lies in that they approach desistance in different ways (see Table 2). The RNR model is based on outcome data regarding program efficacy, whereas the GLM focuses on clinical factors predictions of risk, such as offender agency and the broader community (Laws \& Ward, 2011). If relationships and social capital are considered imperative components of desistance, then this suggests that interventions such as maintenance need to adopt a relational approach (Weaver \& McNeill, 2011). The GLM seems to provide more scope to do this.

The RNR model tends to focus on reducing risk factors, thereby being less likely to focus on assisting offenders to meet a full range of their needs which is necessary for longer term desistance (Polaschek, 2016). For example, an offender may not have the skills necessary to assist him to manage his negative emotional states. However, in the GLM, if the offender is provided with an opportunity to focus on developing his emotional competencies and appropriate social supports, likely to reduce his emotionally driven incidents of sexual offending, then this is considered to have more lasting effects (Laws \& Ward, 2011).

Table 2 - Differences between the RNR and the GLM

\begin{tabular}{|l|l|}
\hline RNR & GLM \\
\hline $\begin{array}{l}\text { Neutral perspective of humankind - learning } \\
\text { and social learning theory }\end{array}$ & $\begin{array}{l}\text { Positive perspective of humankind - } \\
\text { comparable to strain and frustration- } \\
\text { aggression theory }\end{array}$ \\
\hline $\begin{array}{l}\text { Negative orientation to offender client and } \\
\text { task }\end{array}$ & $\begin{array}{l}\text { Positive orientation to offender client and } \\
\text { task }\end{array}$ \\
\hline Risk based - suppress & Strengths based - build \\
\hline Criminogenic needs targeted & Primary needs targeted \\
\hline Objective: management of risk & Objective: life enhancement \\
\hline
\end{tabular}




\begin{tabular}{|l|l|}
\hline Well-being is ‘discretionary' & Well-being is essential \\
\hline $\begin{array}{l}\text { Criminals are different from non-criminals in } \\
\text { many ways (e.g., cognitions, personality) }\end{array}$ & $\begin{array}{l}\text { Criminals are fundamentally the same as } \\
\text { non-criminals; universal underlying values }\end{array}$ \\
\hline
\end{tabular}

Note: Adapted from Wormith, S. (2015, November). RNR and GLM: Shall (or should) ever the twain meet?, The $2^{\text {nd }}$ Annual IACFP Edwin I. Megargee Lecture presentation at the International Community Corrections Association (ICCA) Conference, Boston, Massachusetts.

The effective approach to working with offenders to reduce their dynamic risk factors is to assist offenders in developing protective capabilities and skills that will ameliorate those very factors. This includes encouraging offenders to use these capabilities and skills to desist and otherwise improve their lives (Polaschek, 2016). As Polaschek points out, if the RNRfocused interventions do seek to promote desistance, then the outstanding question remains whether they have an impact on other important psychological and environmental factors involved in the desistance process. It would seem that one of the crucial points along the desistance process is in the early stages of transition, particularly following a period of psychological treatment in custody and then re-entry into the community (Maruna, 2001; Polaschek 2016).

The GLM shares a view with desistance theories that "an effective rehabilitation strategy ought to be holistic in its orientation and attend to individuals' array of social, material, and psychological needs as well as their range of life circumstances" (Laws \& Ward, 2011, p. 224). In practice this means that therapists should pay greater attention to individual, environmental and social factors and contexts of offenders' lives and the impact on their criminal behaviour (Farrall, 2002). The criticism of RNR programs in this respect lies in the narrow focus on factors directly linked to offending behaviour, while neglecting offenders' values, goals and hopes for their lives and futures. There is difficulty in motivating people to change their behaviour by focusing primarily on avoidance goals such as crime cessation (McMurran \& Ward, 2004). 
Another issue concerns the lack of emphasis on the importance of the therapeutic alliance with offenders by RNR focused approaches, given that is it considered to be a pivotal component of effective intervention (Laws \& Ward, 2011; McMurran, 2002; McNeill, 2006; Rex, 1999; Weaver \& McNeill, 2011). While the responsivity principle refers to the use of particular modes to engage offenders in interventions, it is suggested that treatment engagement is not adequately addressed by the RNR model, primarily given its deficit-focus, as opposed to a strengths-focus (Ward \& Brown, 2004). Lastly and perhaps most significantly for the consideration of maintenance programs, the RNR model has been criticised for its lack of focus on personal identity, which has been identified as an integral factor in the desistance research (Maruna, 2001).

A common criticism of both the RNR and the GLM is that both are too focused on the individual level of analysis, with not enough focus on external factors, such as social capital, which is intimately involved in the desistance process (McNeill \& Weaver, 2010; Weaver \& McNeill, 2011). Therefore, interventions aimed at supporting the desistance process need to look beyond just offender management and engagement and address broader issues such as family and social engagement. By developing offenders' positive contributions to families and by working on establishing positive ties within communities, services can create avenues for the generative activities that seem to be important to those desisting from crime in helping them to see themselves as positive contributors to society as opposed to risks (McNeill \& Weaver, 2010).

Though it may appear intuitive to assume, as the GLM suggests, that offenders have a goal-directed pursuit of human needs as everyone else, there is a failure for the GLM to account for what may be directing offenders into criminal trajectories (Porporino \& Fabiano, 2008). The dynamic risk (Andrews \& Bonta, 1998) approach gives some predictive level of explanation for criminal behaviour and attempts to clarify how some people with a particular 
set of dispositional traits exposed to a complex interplay of circumstances can be propelled into antisocial sentiments and lifestyles (Andrews \& Bonta, 1998; Porporino \& Fabiano, 2008). However, both models provide valuable and different input into offending behaviour, which are complimentary to each other. The GLM is a complimentary descriptive model, explaining the type of distortions in goal-directing behaviour which may be characterising anti-social or criminal conduct. RNR explains how this originates and what may be maintaining it. In this sense, both models can contribute to redirecting offenders towards desistance but not either one in isolation and there would appear to be the capacity for desistance theories to also be incorporated when considering community maintenance programs.

\subsection{Conclusion}

A reoccurring theme within the offender rehabilitation literature seems to be that there is a narrow focus on too few approaches, too prematurely and with significant uncertainty as to the real process of change that offenders move through (Porporino, 2013). Often research into change processes for offenders overlooks the fundamentals of general theories as they apply to all humans - general theories of human behaviour are also applicable to offenders. This can limit the research on offender rehabilitation by being too narrow in focus and often failing to apply some of the fundamental psychological theories which also apply to offenders. Predominately, the focus remains on risk factors in the absence of examining how offenders go about constructing new pro-social identities, what might trigger them to do this, what influences the process of change and how a new identity can reconcile the criminal past. Attempts to find 'the' treatment rather than to assist people in making the changes that will meet their goals bares significant limitations.

Some of the issues hindering the effective reintegration of offenders in the community include unresolved tensions between the need to supervise and monitor offenders for the 
purpose of risk management and the need to deliver more personal, positive interventions aimed to encourage and assist offenders to make the necessary internal, intrinsic changes required to ultimately desist. Therefore, although programs attempt to focus on offender reintegration this process remains compromised due to the short-term focus of immediate victim and community protection and the lack of focus on longer term goal of behaviour change and desistance (Flynn, 2010).

An amalgamation of the risk focused approach and the desistance focused approach needs to be considered especially once offenders are released from prison. This may allow for a more holistic approach to offender reintegration and resettlement, which in turn may assist with the desistance process which is the inherent goal of all treatment interventions with offenders. 


\section{References}

ACT Government (2011). Seeing it through: Options for improving offender outcomes in the community. Australia Capital Territory, ACT: Social Policy and Implementation Branch.

Andrews, D. A., \& Bonta, J. (1998). The psychology of criminal conduct ( $2^{\text {nd }}$ ed). Anderson Publishing Co: Cincinnati, $\mathrm{OH}$.

Andrews, D. A., \& Bonta, J. (2010). The psychology of criminal conduct ( $5^{\text {th }}$ ed). New Providence, NJ: Matthew Bender \& Company Inc.

Andrews, D., \& Dowden, C. (2007). The risk-need-responsivity model of assessment and human service in prevention and corrections: Crime-prevention jurisprudence. Canadian Journal of Criminology and Criminal Justice, 439-464.

Bandura, A. (1977). Self-efficacy: Toward a unifying theory of behaviour change. Psychological Review, 84, 275-279.

Bates, A., Williams, D., Wilson, C., \& Wilson, R. (2014). Circles south east: The first 10 years 2002-2012. International Journal of Offender Therapy and Comparative Criminology, 58, 861-885.

Borzycki, M., \& Baldry, E. (2003). Promoting integration: The provision of prisoner postrelease services. Trends and Issues in Crime and Criminal Justice, No. 262. Canberra, Australia: Australian Institute of Criminology.

Bushway, S., Piquero, A., Broidy, L., Cauffman, E., \& Mazerolle, P. (2001). An empirical framework for studying desistance as a process. Criminology, 39, 491-516.

Carich, M., Wilson, C., Carich, P., \& Calder, M. (2013). Contemporary sex offender treatment: incorporating circles of support and the good lives model. In J. Brayford, F. Cowe, \& J. Deering (Eds), What else works? Creative work with offenders, (pp. 188210). Hoboken: Taylor and Francis. 
Casey, S., Day, A., \& Howells, K. (2005). The application of the transtheoretical model to offender populations: Some critical issues. Legal and Criminological Psychology, 10, $157-171$.

Clarke, R., \& Cornish, D. (1985). Modelling offenders' decisions: A framework for policy and research. In M. Tonry (Ed), Crime and Justice, Vol 6. Chicago: University Press.

Cumming, G. \& Buell, M. (1996). Relapse prevention as a supervision strategy for sex offenders. Sexual Abuse: A Journal of Research and Treatment, 8, 231-241.

Day. A., \& Casey. S. (2010). Maintenance programs for forensic clients. Psychology, Crime and Law 16, 1-10.

Evans, I. (2013). How and why people change: Foundations of psychological therapy. USA: Oxford University Press.

Farrall, S. (2002). Rethinking what works with offenders: Probation, social context and desistance from crime. Cullompton: Willan.

Farrall, S., Sharpe, G., Hunter, B., \& Calverley, A. (2011). Theorizing structural and individual-level processes in desistance and persistence: Outlining an integrated perspective. Australian \& New Zealand Journal of Criminology, 44, 218-234.

Ferguson, J. (2002). Putting the "what works" research into practice: An organisational perspective. Criminal Justice and Behaviour, 29, 472-491.

Fleig, L., Pomp, S., Schwarzer, R., \& Lippke, S. (2013). Promoting exercise maintenance: How interventions with booster sessions improve long-term rehabilitation outcomes. Rehabilitation Psychology, 58, 323-333.

Flynn, N. (2010). Criminal Behaviour in context: Space, place and desistance from crime. New York: Willan Publishing.

Fukuyama, F. (2001). Social capital, civil society and development. Third World Quarterly, 22, 7-20. 
Glueck, S., \& Glueck, E., (1974). Of delinquency and crime. Springfield, Illinois: Charles C. Thomas.

Gottfredson, M., \& Hirschi, T. (1990). A general theory of crime. Stanford, C. A.: Stanford University Press.

Gove, W., (1985). The affect of age and gender on deviant behaviour: A biopsychosocial perspective. In A. Rossi (Ed), Gender and the life course (pp.115-144). New York: Adeline.

Hanson, K. \& Harris, A. (1998). Dynamic predictors of sexual recidivism. Ottawa: Department of the Solicitor General Canada.

Harkins, L., Flak, V., Beech, A., \& Woodhams, J. (2012). Evaluation of a community-based sex offender treatment program using a good lives model approach. Sexual Abuse, 24, $519-543$.

Healy, D. (2010). The dynamics of desistance: Charting pathways through change. Cullompton: Willan.

Hennessy, M., Bolan, G., Hoxworth, T., Iatesta, M., Rhodes, F. \& Zenilman, J. (1999). Using growth curves to determine the timing of booster sessions. Structural Equation Modelling, 6, 322-342.

Hesteltine, K., Day, A., \& Sarre, R. (2009). Prison-based correctional rehabilitation: An overview of intensive interventions for moderate to high-risk offenders. Trends and issues in Crime and Criminal Justice, no.412. Canberra: Australian Institute of Criminology.

Howells, K., Hesteltine, K., Sarre, R., Davey, L., \& Day, D. (2004). Correctional offender rehabilitation programs: The National picture in Australia. Forensic Psychology Research Group, Centre for Applied Psychological Research: University of South Australia. 
James, C., Stams, G., Asscher, J., De Roo, A., \& van der Laan, P (2013). Aftercare programs for reducing recidivism among juvenile and young adult offenders: A meta-analytic review. Clinical Psychology Review, 33, 263-274.

Jonson, C., \& Cullen, F. (2015). Prisoner reentry programs. Crime and Justice, 44, 517 - 575.

Laub, J., \& Sampson, R. (2001). Understanding desistance from crime. Crime and Justice, $28,1-69$.

Laws, D. (2003). The rise and fall of relapse prevention. Australian Psychologists, 38, 22-30.

Laws, R., Hudson, S., \& Ward, T. (2000). The original model of relapse prevention with sex offenders: Promises unfulfilled. In R. Laws, S. Hudson, \& T. Ward (Eds), Remaking relapse prevention with sex offenders: A sourcebook, (pp.3-26). California: Sage Publications.

Laws, R. D. \& Ward, T. (2011). Desistance from sex offending: Alternatives to throwing away the keys. New York: Guildford Press.

Mann, R., \& Fernandez, Y. (2006). Sex offender programmes: concept, theory, and practice.

In C. Hollin \& E. Palmer (Eds), Offending behaviour programmes: Development, application, and controversies, (pp.155-178). West Sussex, England: John Wiley \& Sons, Ltd.

Maslow, A. H. (1943). A Theory of human motivation. Psychological Review, 50, 370-96.

Maslow, A. H. (1954). Motivation and personality. New York: Harper and Row.

Marlatt, G. \& Gordon, J. (1985). Relapse Prevention: Maintenance Strategies in the Treatment of Addictive Behaviors. New York: Guilford Press.

Marshall, W., \& Marshall, L. (2014). Psychological treatment of sex offenders: Recent innovations. Sexual Deviation: Assessment and Treatment, 37, 163-171.

Martin, K. (2012). The transtheoretical model of behaviour change and possible selves in 
criminal offenders. Unpublished doctoral thesis, University of Toronto.

Maruna, S. (2001). Making good: How ex-convicts reform and rebuild their lives. Washington, D.C.: American Psychological Association.

McMurran, M. (2002). Motivation of change: Selection criterion or treatment need?. In M. McMurran (Ed), Motivating offenders to change: A guide to enhancing engagement in therapy, (pp. 3-13). UK: John Wiley and Sons.

McMurran, M., \& Ward, T. (2004). Motivating offenders to change in therapy: A organising framework. Legal and Criminological Psychology, 9, 295-311.

McNeill, F. (2006). A desistance paradigm for offender management. Criminology and Criminal Justice, 6, 39-62.

McNeill, F., \& Weaver, B. (2010). Changing lives? Desistance research and offender management. Glasgow: The Scottish Centre for Crime and Justice Research.

Moffitt, T. (1994). Natural histories of delinquency. In E. Weitkamp \& H. Kerner (Eds), Cross-national longitudinal research on human development and criminal behaviour, (pp. 3-61). The Netherlands: Kluwer Academic.

Paternoster, R. (1989). Decision to participate in and desist from four types of common delinquency: Deterrence and the rational choice perspectives. Law and Society Review, 23, 7-40.

Paul, H. (2014). How and why people change: Foundations of psychological therapy, by I. M. Evans. Child and Family Behavior Therapy, 36, 236-243.

Payne, C. L., (2008). Pathways to sex offending: Etiology and the offence process. Unpublished doctoral thesis, Deakin University, Melbourne, Victoria, Australia.

Pithers, W.D. (1990). Relapse prevention with sexual aggressors: A method for maintaining therapeutic gain and enhancing external supervision. In W.L. Marshall, D.R. Laws, \& H.E. Barbaree (Eds.), Handbook of sexual assault: Issues, theories and treatment of 
the offender (pp.346-361). New York: Plenum. Polaschek, D. (2016). Desistance and dynamic risk factors belong together. Psychology, Crime and Law, 22, 171-189.

Porporino, F. (2013). Bringing sense and sensitivity to corrections: From programmes to 'fix' offenders to services to support desistance. In J. Brayford, F. Cowe, \& J. Deering (Eds), What else works? Creative work with offenders (pp. 61-85). Hoboken: Taylor and Francis.

Porporino, F., \& Fabiano, E., (2008). Case managing offenders within a motivational framework. In G. McIvor \& P. Raynor (Eds), Developments in social work with offenders (pp.184-211). London: Jessica Kingsley.

Rex, S. (1999). Desistance from offending: experience of probation. The Howard Journal, 38, 366-383.

Sampson, R., \& Laub, J. (1993). Crime in the making: pathways and turning points through life. Cambridge, MA: Harvard University Press.

Sampson, R., \& Laub, J. (2004). Desistance from crime over the life course. In J. Mortimer \& M. Shanahan, (Eds), Handbook of the life course, (pp.311-330). USA: Springer.

Shover, N. (1996). Great pretenders: Pursuits and careers of persistent thieves. Boulder, Colo.: Westview Press.

Taxman, R, \& Bouffard, J. (2000). The Importance of System Issues in Improving Offender Outcomes: Critical Elements of Treatment Integrity. Justice Research \& Policy 2, 930.

Thakker, J., \& Ward, T. (2010). Relapse prevention: A critique and proposed reconceptualisation. Behaviour Change, 27, 154-175.

Turner, S. (2010). Case management in corrections: evidence, issues and challenges. In F. McNeill, P. Raynor \& C. Trotter (Eds), Offender supervision: New direction in theory, research and practice, (pp.344-366). New York: Willan Publishing. 
Vasey, M., \& Dadds, M. (2001). The developmental psychopathology of anxiety. New York: Oxford University Press.

Vaterlaus, M. (2009). Perceived effectiveness of booster sessions following a stepfamily education course. All graduate theses and dissertations, Paper-445. Logan, Utah: Utah State University.

Ward, T. (2002). Good lives and the rehabilitation of offenders: Promises and problems. Aggression and Violent Behavior, 7, 513-528.

Ward, T., \& Brown, M. (2004). The good lives model and conceptual issues in offender rehabilitation. Psychology, Crime and Law, 10, 243-257.

Ward, T., Gannon, T. \& Mann, R. (2007). The Good Lives Model of Offender Rehabilitation: Clinical Implications. Aggression and Violent Behavior, 12, 87-107.

Ward, T. and Maruna, S. (2007). Rehabilitation: beyond the risk paradigm. London: Routledge.

Ward, T., Polaschek, D., \& Beech, A. (2006). Theories of sexual offending. New Jersey: John Wiley \& Sons.

Ward, T., Purvis, M., \& Devilly, G. (2004). Relapse prevention: theory and practice. In H. Kemshall \& G. McIvor (Eds), Managing sex offender risk, (pp. 187-208). London: Jessica Kingsley Publishers.

Ward, T., \& Stewart, C. A. (2003a). The treatment of sex offenders: Risk management and good lives. Professional Psychology, Research and Practice, 34, 353-360.

Ward, T., \& Stewart, C. A. (2003b). Criminogenic needs and human needs: A theoretical model. Psychology, Crime \& Law, 9, 125-143.

Warr, M. (1998). Life-course transitions and desistance from crime. Criminology, 36, 183216. 
Weaver, B., \& McNeill, F. (2007). Giving up crime: Directions for policy. Scottish Consortium on Crime and Criminal Justice: Edinburgh.

Weaver, B., \& McNeill, G. (2011). Some lessons from research organising and delivering case management work with offenders. Conference, September 2011. The Scottish Centre of Crime and Justice Research. http://cep-probation.org/wpcontent/uploads/2015/03/DOMICE-desistance-and-case-management1.pdf

Weaver, B., \& McNeill, F. (2013). Travelling hopefully: Desistance theory and probation practice. In J. Brayford, F. Cowe, \& J. Deering (Eds), What else works? Creative work with offenders (pp. 36-60). Hoboken: Taylor and Francis.

Willis, G., \& Grace, R. (2008). The quality of community reintegration planning for child molesters: Effects on sexual recidivism. Sexual Abuse: A Journal of Research and Treatment, 20, 218-240.

Willis, G., \& Grace, R. (2009). Assessment of Community reintegration planning for sex offenders: Poor planning predicts recidivism. Criminal Justice and Behavior, 36, 494512.

Wilson, R., Cortoni, F., \& McWhinnie, A. (2009). Circles of support and accountability: A Canadian replication of outcome findings. Sexual Abuse: A Journal of Research and Treatment, 21, 412-430.

Wilson, R. \& Picheca, J. E. (2005). Circles of support and accountability: engaging the community in sexual offender risk management. In B. K. Swartz (Ed), The Sexual Offender, (pp. 13.1-13.21) Vol 5, New York: Civic Research Institute.

Wilson, R. J., Picheca, J. E., \& Prinzo, M. (2005). Circles of support and accountability: An evaluation of the pilot project in south central Ontario. Research report R. 168. Ottawa ON: Correctional Service of Canada 
Wilson, R., Stewart, L., Stirpe, T., Barrett, M., \& Cripps, J. (2002). Community-based sex offender management: Combining parole supervision and treatment to reduce recidivism. Canadian Journal of Criminology, 177-188.

Wormith, S. (2015). RNR and GLM: Shall (or should) ever the twain meet? The $2^{\text {nd }}$ Annual IACFP Edwin I. Megargee lecture presentation. International Community Corrections Association (ICCA) Conference. Boston, Massachusetts.

Youssef, C. (2013). Community maintenance programs for sexual offenders. Journal of Offender Rehabilitation, 52, 217-232. 